\title{
Mechanic Stress Generated by a Time-Varying Electromagnetic Field on Bone Surface
}

Hui Ye

Loyola University Chicago, hye1@luc.edu

Follow this and additional works at: https://ecommons.luc.edu/biology_facpubs

Part of the Biology Commons

Author Manuscript

This is a pre-publication author manuscript of the final, published article.

\section{Recommended Citation}

Ye, Hui. Mechanic Stress Generated by a Time-Varying Electromagnetic Field on Bone Surface. Medical \& Biological Engineering \& Computing, 56, 10: 1793-1805, 2018. Retrieved from Loyola eCommons, Biology: Faculty Publications and Other Works, http://dx.doi.org/10.1007/s11517-018-1814-3

This Article is brought to you for free and open access by the Faculty Publications and Other Works by Department at Loyola eCommons. It has been accepted for inclusion in Biology: Faculty Publications and Other Works by an authorized administrator of Loyola eCommons. For more information, please contact ecommons@luc.edu. cc) (i) $\Theta$

This work is licensed under a Creative Commons Attribution-Noncommercial-No Derivative Works 3.0 License. (C) International Federation for Medical and Biological Engineering 2018 


\section{Medical \& Biological Engineering \& Computing Mechanic stress generated by a time-varying electromagnetic field on bone surface --Manuscript Draft--}

\begin{tabular}{|c|c|}
\hline \multicolumn{2}{|l|}{ Manuscript Number: } \\
\hline Full Title: & Mechanic stress generated by a time-varying electromagnetic field on bone surface \\
\hline Article Type: & Original article \\
\hline Keywords: & Time-varying magnetic field; Bone; Biomechanics; Stress. \\
\hline Corresponding Author: & $\begin{array}{l}\text { Hui Ye } \\
\text { Loyola University Chicago } \\
\text { Chicago, UNITED STATES }\end{array}$ \\
\hline \multicolumn{2}{|l|}{$\begin{array}{l}\text { Corresponding Author Secondary } \\
\text { Information: }\end{array}$} \\
\hline Corresponding Author's Institution: & Loyola University Chicago \\
\hline \multicolumn{2}{|l|}{$\begin{array}{l}\text { Corresponding Author's Secondary } \\
\text { Institution: }\end{array}$} \\
\hline First Author: & Hui Ye \\
\hline \multicolumn{2}{|l|}{ First Author Secondary Information: } \\
\hline Order of Authors: & Hui Ye \\
\hline \multicolumn{2}{|c|}{ Order of Authors Secondary Information: } \\
\hline \multicolumn{2}{|l|}{ Funding Information: } \\
\hline Abstract: & $\begin{array}{l}\text { Cells sense mechanical load, which is essential for bone growth and remodeling. In a } \\
\text { fracture, this mechanism is compromised. Electromagnetic stimulation has been widely } \\
\text { used to assist in bone healing, but the underlying mechanisms are largely unknown. } \\
\text { Recent hypothesis suggests that electromagnetic stimulation could influence bone } \\
\text { biomechanics, however, a detailed quantitative understating of EM-induced } \\
\text { biomechanical changes in the bone is unavailable. This paper used a muscle/bone } \\
\text { model to study the biomechanics of the bone under EM exposure. Due to the dielectric } \\
\text { properties of the muscle/bone interface, the magnetic field generates both } \\
\text { compressing and shear stresses on the bone surface, where many mechanical } \\
\text { sensing cells are available for cellular mechanotransduction. I calculated these } \\
\text { stresses under a time-varying electromagnetic field. The shear stress is significantly } \\
\text { greater than the compressing stress, suggesting the physiological effect of EM is } \\
\text { probably via the shear stress - related mechanism. Detailed parametric analysis } \\
\text { suggests that both the compressing and shear stresses are dependent on the } \\
\text { geometrical and electrical properties of the muscle and the bone. These stresses are } \\
\text { also functions of the orientation of the coil, and the frequency of the magnetic field. } \\
\text { Therefore, the biomechanical influence of the EM field on fractured bone can be } \\
\text { optimized through the fine-tuning of these controllable field parameters. }\end{array}$ \\
\hline \multirow[t]{3}{*}{ Suggested Reviewers: } & $\begin{array}{l}\text { Stiliyan Kalitzin } \\
\text { Epilepsy Institutes of The Netherlands Foundation } \\
\text { skalitzin@sein.nl } \\
\text { Kalitzin is a phycist who is interested with electric stimulation. }\end{array}$ \\
\hline & $\begin{array}{l}\text { Marom Bikson } \\
\text { City College of New York } \\
\text { bikson@ccny.cuny.edu } \\
\text { Dr. Bikson is an expert in brain stimulation with electric current. }\end{array}$ \\
\hline & $\begin{array}{l}\text { Dominique Durand } \\
\text { Case Western Reserve University } \\
\text { dominique.durand@case.edu } \\
\text { Dr. Durand is an neural engineering expert and has many publications on } \\
\text { electromagnetic stimulation. }\end{array}$ \\
\hline
\end{tabular}




\section{Mechanic stress generated by a time-varying electromagnetic field on}

\section{bone surface}

Hui Ye

Departments of Biology, Loyola University Chicago

1032 W. Sheridan Rd., Chicago, IL 60660

\section{Correspondence:}

Hui Ye, Ph.D.

Department of Biology

Loyola University Chicago

Quinlan Life Sciences Education and Research Center

1032 W. Sheridan Rd., Chicago, IL 60660

Tel (773) 508-2720

Email: hye1@luc.edu

\section{Abstract}

Cells sense mechanical load, which is essential for bone growth and remodeling. In a fracture, this mechanism is compromised. Electromagnetic stimulation has been widely used to assist in bone healing, but the underlying mechanisms are largely unknown. Recent hypothesis suggests that electromagnetic stimulation could influence bone biomechanics, however, a detailed quantitative understating of EM-induced biomechanical changes in the bone is unavailable. This paper used a muscle/bone model to study the biomechanics of the bone under EM exposure. Due to the dielectric properties of the muscle/bone interface, the magnetic field generates both compressing and shear stresses on the bone surface, where many mechanical sensing cells are available for cellular mechanotransduction. I calculated these stresses under a time-varying electromagnetic field. The shear stress is significantly greater than the compressing stress, suggesting the physiological effect of EM is probably via the shear stress - related mechanism. Detailed parametric analysis suggests that both the compressing and shear stresses are dependent on the geometrical and electrical properties of the muscle and the bone. These stresses are also functions of the orientation of the coil, and the frequency of the magnetic field. Therefore, the biomechanical influence of the EM field on fractured bone can be optimized through the fine-tuning of these controllable field parameters.

\section{Keywords}

Time-varying magnetic field; Bone; Biomechanics; Stress.

\section{Introduction}

Mechanic load plays a pivotal role in bone formation and remodeling [12]. Strain gradients are created when bone is subjected to mechanical stress, which results in an interstitial fluid drive through the canaliculi and exposes osteocyte membrane to flow-related shear stress, as well as to electric potentials subsequent to the streaming process [17]. The mechanical environment regulates osteogenesis and enhances bone formation. Modulation of loading can accelerate callus formation and remodeling [31]. The mechanical influence on skeletal tissue differentiation 
is defined by the applied load, local stress, and strain levels in the loaded tissue. Reduction in loading on the bone, during long-term immobilization or microgravity, can result in significant bone loss [32,33]. When bone is fractured, both the mechanical load to the bone and the distribution of electric potentials in the bone are altered.

The two invariants in mechanical loading are hydrostatic stress and octahedral shear stress. The hydrostatic stress is normal to the bone surface. Both the normal, hydrostatic stress [5] [8] and the shear stress have been identified as the key stimulating mechanical forces $[44,29,30]$ that contribute to tissue differentiation in the healing of fractured bone [18]. Compressive hydrostatic stress history guides the formation of cartilaginous matrix constituents, and tensile strain history guides connective tissue cells in their production and turnover of fibrous matrix constituents [42]. Shear stress, on the other hand, is thought to have a different function. Under physiological conditions, the shear stress on the bone surface is primarily caused by friction between fluid particles due to fluid viscosity. Flow shear causes an increase in intracellular calcium $\left(\left[\mathrm{Ca}_{2+}\right]_{i}\right)$ in osteoblastic cells through the activation of mechanosensitive and voltagesensitive $\mathrm{Ca}^{2+}$ channels [47]. Pauwels suggested that cell and extracellular matrix elongation associated with distortional shear stress constitutes a specific stimulus for the development of collagen fibers [42]. Shear movement at the fracture site has been found to play an important role in bone healing of diaphyseal tibial fractures [50].

Electric stimulation has gained unanimous clinical success in bone healing since the pioneer work of Yusuda (1953), who applied a continuous current to a rabbit femur to assist newbone formation [9]. Using animal models, Pulsed electromagnetic field stimulation (PEMF) was proved to be one of the most efficient method in enhancing new bone formation [61]. Clinically, it was found that electric stimulation is effective in fresh fractures and osteotomies, spine fusion, as well as nonunion fractures [7]. A variety of instruments have been developed to deliver electric currents to the fracture site, including invasive direct-current (DC) stimulators, noninvasive capacitive coupling (CC) stimulators, and noninvasive induced coupling (IC) stimulators, which produces PEMF. Among these designs, the IC technique is the most popular one. Applied through a single or double coil and driven by an external field generator, the treatment effects of the stimulation are due to a secondary electrical field produced in the bone. The induced electric field intensity in this practice could reach 1-100 $\mathrm{mV} / \mathrm{cm}$ [1]. However, mechanisms of how the exogenously applied, time-varying electromagnetic fields assist in bone healing remain largely elusive. It is thought that EM fields assist bone healing through the same principle as mechanical stress [17]. It is not known, however, how the electric signal is converted to the mechanic signal when the bone is under time-varying EM stimulation.

To obtain a quantitative estimation of the cellular biomechanics under time-varying EM stimulation, I will model a limb as a conductive body, with cylindrical-like bone embedded inside the muscle. I will calculate the mechanical stress distribution on the bone surface, including the physiologically relevant stress that is normal to the bone surface, as well as the shear stress. The EMF is generated by a single coil, which produces a time-varying EM field inside the muscle/bone area.

\section{Method}

\subsection{Cylindrical bone model in a time-varying magnetic field}

Figure $1 \mathrm{~A}$ shows the basic geometry for a cylindrical limb under a time-varying magnetic field that is generated by a single magnetic coil, such as that used in magnetic biostimulation therapy (http://www.innovativetherapycanada.com/show.magnetic-biostimulation.html\#). The 
field was generated by a round coil and the limb was positioned perpendicular to the plane of the coil. Therefore, the magnetic field generated by the coil was parallel to the limb in the plane defined by the coil, and the electric field induced by the magnetic field was transverse to the limb (Figure 1B). The model considers three homogenous, isotropic regions: the air (A), the muscle (M) and the bone (B). The limb was represented in a cylindrical coordinate system $(r, \theta, z)$ centered at point $O$. The center of the bone overlapped with this point. The dielectric permittivities and conductivities in the three regions were $\varepsilon_{A}, \varepsilon_{M}, \varepsilon_{B}$ and $\sigma_{A}, \sigma_{M}, \sigma_{B}$, respectively. The radius of the limb was $R_{M}=5 \mathrm{~cm}$ and the radius of the bone was $R_{B}=2.5 \mathrm{~cm}$ (Figure 1C).

The magnetic field was initially represented in a cylindrical coordinate system $\left(r^{\prime}, \theta^{\prime}, z^{\prime}\right)$. The distance between the center of the bone $(O)$ and the center of the round coil $\left(O^{\prime}\right)$ was $C$. The magnetic field was a sinusoidally alternating field. It was symmetric about the $O^{\prime} Z^{\prime}$ axis, in the negative $O^{\prime} Z^{\prime}$ direction. Mathematically, the magnetic field was represented as $\vec{B}=-\vec{Z}^{\prime} B_{0} e^{j \omega t}$ , where $\vec{Z}^{\prime}$ was the unit vector in the direction of $O^{\prime} Z^{\prime}, \mathrm{B}_{0}$ was the field intensity, and $\omega$ was the angular frequency of the magnetic field.

\subsection{Model parameters}

The dielectric properties of the air, muscle and bone were obtained from literature.

Air: The conductivity of air is $\sigma_{A}=3 \times 10^{-15} \mathrm{~S} / \mathrm{m}$ to $8 \times 10^{-15} \mathrm{~S} / \mathrm{m}$ at $20{ }^{0} \mathrm{C}$ [48]. The permittivity of air is $\varepsilon_{\mathrm{A}}=8.854 \times 10^{-12} \mathrm{~F} \cdot \mathrm{m}^{-1}[51]$.

Muscle: The conductivity of buck meat is $\sigma_{M}=2.5 \mathrm{~S} / \mathrm{m}$ [35]. The dielectric constant of the muscle is $\varepsilon_{M}=51 \varepsilon_{A}$ (at $915 \mathrm{MHz}$ ) [41].

Bone: The resistivity is about $45-48 \Omega \cdot m$ in the longitudinal direction, and three to four times greater in the radial direction [6]. Therefore, the conductivity of the bone in the radial direction is $\sigma_{B}=1 /\left(4^{*} 45\right) \mathrm{S} / \mathrm{m}=5.6 \times 10^{-3} \mathrm{~S} / \mathrm{m}$. The dielectric permittivity is $100000\left(X \varepsilon_{0}=8.854\right.$ $\left.\times 10^{-12} \mathrm{~F} \cdot \mathrm{m}^{-1}\right)$ for the bone [45]. Therefore, $\varepsilon_{B}=8.854 \times 10^{-7} \mathrm{~F} \cdot \mathrm{m}^{-1}$.

The distance between the center of the bone and the center of the coil is $C=10 \mathrm{~cm}=$ $0.1 \mathrm{~m}$. The induced electric field intensity was chosen to be $100 \mathrm{mV} / \mathrm{cm}$ [1]. Since $E=-j \frac{\omega B_{0} C}{2}$ (Polk 1990), $\omega B_{0}=200 \mathrm{~V} / \mathrm{m}^{2}$. The frequency range was determined to be between $2 \mathrm{kHz}-200$ $\mathrm{kHz}$. The upper limit $(200 \mathrm{KHz})$ was determined by calculating the reciprocal value of the rising phase of a current pulse during peripheral nerve stimulation $[27,46]$. Most frequencies used in experimental practices have been lower than this value [38]. In addition, the $50 \mathrm{~Hz}$ power line frequency was given attention, since many magnetic stimulators generate a signal at this frequency.

\subsection{Governing equations for potentials induced by a time-varying magnetic field}

The electric field induced by a time-varying magnetic field in biological media was

$$
\vec{E}=-j \omega \vec{A}-\nabla V
$$

where $\vec{A}$ was the magnetic vector potential induced by the current source. The potential $V$ was the electric scalar potential due to charge accumulation that appeared from the application of a 
time-varying magnetic field [54]. In cylindrical coordinates $(r, \theta, z), \nabla V=\left(\frac{\partial V}{\partial r}, \frac{1}{r} \frac{\partial V}{\partial \theta}, \frac{\partial V}{\partial z}\right)$. For low frequency stimulation, we can use quasi-static approximations. Therefore, in charge-free regions, $V$ was obtained by solving Laplace's equation

$$
\nabla^{2} V=0
$$
form

In cylindrical coordinates $(r, \theta, z)$, the solution for Laplace's equation (2) was written in the

$$
V_{n}=\left(\frac{A_{n}}{r}+D_{n} r\right) \sin \theta
$$

where $A_{n}, D_{n}$ were unknown coefficients in the three modeled regions $(n=A, M, B)$. These coefficients were solved in the Appendix.

\subsection{Boundary conditions}

Four boundary conditions were considered in the derivation of the potential induced by the time-varying magnetic field.

(A). The potential was continuous across the boundary of two different media.

(B). The normal component of the current density was continuous across two different media. During time-varying field stimulation, the "complex conductivity", defined as $S=\sigma+j \omega \varepsilon$, was used to account for the dielectric permittivity of the material $[43,26,25]$. Here, $\sigma$ was the conductivity of the tissue, $\varepsilon$ was the permittivity, $\omega$ was the angular frequency of the field, and $j=\sqrt{-1}$ was the imaginary unit. Therefore, on the air/muscle (AM) interface,

$$
S_{A} E_{A r}-S_{M} E_{M r}=0
$$

On the muscle/bone (MB) interface,

$$
S_{M} E_{M r}-S_{B} E_{B r}=0
$$

in which $S_{A}=\sigma_{A}+j \omega \varepsilon_{A}, S_{M}=\sigma_{M}+j \omega \varepsilon_{M}, S_{B}=\sigma_{B}+j \omega \varepsilon_{B}$ were the complex conductivities of the three media, respectively.

(C). The electric field at an infinite distance from the limb was not perturbed by the presence of the limb in the magnetic field.

(D). The potential inside the limb $(r=0)$ was finite.

\subsection{Magnetic vector potential $\vec{A}$}

At point $O^{\prime}, \vec{B}$ was in the direction of $-\vec{Z}^{\prime}$ and

$$
\vec{B}=\nabla \times \vec{A}
$$

where vector potential $\vec{A}$ was in the direction of - $\vec{\phi}^{\prime}$ (Figure 1). In cylindrical coordinates $\left(r^{\prime}, \theta^{\prime}, z^{\prime}\right.$ ), the magnetic vector potential was expressed as:

$$
\vec{A}^{\prime}=-\frac{r^{\prime} B_{0}}{2} e^{j \omega t} \vec{\theta}^{\prime}
$$


In order to calculate the potential distribution in the modeled limb, an expression for $\vec{A}$ in cylindrical coordinates $(r, \theta, z)$ was necessary. Through coordinate transformation, the magnetic vector potential $\vec{A}$ in cylindrical coordinates $(r, \theta, z)$ became

$$
\vec{A}=\vec{r} A_{o r}+\vec{\theta} A_{o \theta}+\vec{z} A_{o z}
$$

The vector potential components in the $\vec{r}, \vec{\theta}, \vec{\phi}$ directions were [57]:

$$
\begin{aligned}
& A_{o r}=\frac{B_{0}}{2} C \sin \theta \\
& A_{o \theta}=-\frac{B_{0}}{2}(r-C \cos \theta) \\
& A_{o z}=0
\end{aligned}
$$

\subsection{Surface charges and electric stress}

At the boundary between two inhomogeneous media with distinct electrical properties, free charges accumulated and caused a discontinuity in the normal components of the displacement vector. At the air/muscle interface $\left(\mathrm{r}=\mathrm{R}_{\mathrm{M}}\right)$

$$
\rho_{A M}=\vec{n} \bullet\left(\varepsilon_{M} \vec{E}_{M}-\varepsilon_{A} \vec{E}_{A}\right) \text { or } \rho_{A M}(R, \theta, \phi)=\varepsilon_{M} E_{M r}-\varepsilon_{A} E_{A r}
$$

At the muscle/bone interface $\left(\mathrm{r}=\mathrm{R}_{\mathrm{B}}\right)$

$$
\rho_{M B}=\vec{n} \bullet\left(\varepsilon_{B} \vec{E}_{B}-\varepsilon_{M} \vec{E}_{M}\right) \text { or } \rho_{M B}(R, \theta, \phi)=\varepsilon_{M} E_{M r}-\varepsilon_{B} E_{B r}
$$

where $\vec{n}$ denoted the outward unit normal vector, $\rho_{A M}$ and $\rho_{S M B}$ denoted the charge densities on the two interfaces, respectively.

The electric stress generated on the membrane was a result of the interaction between the free charges and the induced electric field. The stress includes two components: the normal stress and the shear stress. The normal stress arises from the force vector component perpendicular to the material cross section on which it acts. It equals the product of the charge and the average of the electric fields on both sides of the bone surface [15]. At the muscle/bone interface $\left(r=R_{B}\right)$,

$$
P_{r B M}=\frac{1}{2}\left(E_{r B}+E_{r M}\right) \rho_{M B}
$$

The shear stress, on the other hand, is defined as the component of stress coplanar with a material cross section. Shear stress arises from the force vector component parallel to the cross section and is tangent to the bone surface. On the muscle/bone interface $\left(r=R_{B}\right)$,

$$
P_{\theta B M}=E_{\theta B} \rho_{M B}
$$

\section{Results}

\subsection{Electric field distribution inside and around the bone}

Electric field inside the muscle/bone structure is generated by electromagnetic induction. In addition, the presence of biological tissue, which has inhomogeneous electric properties, redistributes the induced current around the bone [60] [34]. It is therefore not a surprise that the induced electric fields are dependent on both the properties of the magnetic field and the electric properties of the muscle and the bone.

In the air surround the limb, 


$$
\begin{aligned}
& E_{A r}=\frac{1}{2} B_{0} C j \omega\left\{-1+\frac{R_{M}{ }^{2}\left[R_{B}{ }^{2}\left(S_{A}+S_{M}\right)\left(S_{M}-S_{B}\right)+R_{M}{ }^{2}\left(S_{A}-S_{M}\right)\left(S_{M}+S_{B}\right)\right]}{\left[R_{B}{ }^{2}\left(S_{A}-S_{M}\right)\left(S_{M}-S_{B}\right)+R_{M}{ }^{2}\left(S_{A}+S_{M}\right)\left(S_{M}+S_{B}\right)\right] r^{2}}\right\} \sin \theta \\
& E_{A \theta}=\frac{1}{2} B_{0} j \omega\left\{r-C \cos \theta-\frac{C R_{M}{ }^{2}\left[R_{B}{ }^{2}\left(S_{A}+S_{M}\right)\left(S_{M}-S_{B}\right)+R_{M}{ }^{2}\left(S_{A}-S_{M}\right)\left(S_{M}+S_{B}\right)\right]}{\left[R_{B}{ }^{2}\left(S_{A}-S_{M}\right)\left(S_{M}-S_{B}\right)+R_{M}{ }^{2}\left(S_{A}+S_{M}\right)\left(S_{M}+S_{B}\right)\right] r^{2}} \cos \theta\right\}
\end{aligned}
$$

$$
E_{A z}=0
$$

In the muscle:

$$
\begin{aligned}
& E_{M r}=j \omega B_{0} C \frac{R_{M}^{2} S_{A}\left[R_{B}{ }^{2}\left(S_{M}-S_{B}\right)+\left(S_{M}+S_{B}\right) r^{2}\right]}{\left[R_{B}{ }^{2}\left(S_{A}-S_{M}\right)\left(S_{M}-S_{B}\right)+R_{M}{ }^{2}\left(S_{A}+S_{M}\right)\left(S_{M}+S_{B}\right)\right] r^{2}} \sin \theta \\
& E_{M \theta}=\frac{1}{2} j \omega B_{0}\left[r-\frac{2 C R_{M}{ }^{2} S_{A}\left[R_{B}{ }^{2}\left(S_{M}-S_{B}\right)+\left(S_{M}+S_{B}\right) r^{2}\right] \cos \theta}{\left[R_{B}{ }^{2}\left(S_{A}-S_{M}\right)\left(S_{M}-S_{B}\right)+R_{M}{ }^{2}\left(S_{A}+S_{M}\right)\left(S_{M}+S_{B}\right)\right] r^{2}}\right] \\
& E_{M z}=0
\end{aligned}
$$

Inside the bone:

$$
\begin{aligned}
& E_{B r}=-\frac{2 B_{0} C j \omega R_{M}{ }^{2} S_{A} S_{M}}{R_{B}{ }^{2}\left(S_{A}-S_{M}\right)\left(S_{M}-S_{B}\right)+R_{M}{ }^{2}\left(S_{A}+S_{M}\right)\left(S_{M}+S_{B}\right)} \sin \theta \\
& E_{B \theta}=\frac{1}{2} B_{0} j \omega\left[r-\frac{4 C R_{M}{ }^{2} S_{A} S_{M} \cos \theta}{R_{B}{ }^{2}\left(S_{A}-S_{M}\right)\left(S_{M}-S_{B}\right)+R_{M}{ }^{2}\left(S_{A}+S_{M}\right)\left(S_{M}+S_{B}\right)}\right] \\
& E_{B z}=0
\end{aligned}
$$

It is clear that $E_{M \theta}=E_{B \theta}$ at the bone/muscle boundary $\left(\mathrm{r}=\mathrm{R}_{\mathrm{B}}\right)$.

\subsection{Distribution of magnetically-induced surface charges}

Under electromagnetic field stimulation, surface charge accumulated on the interface of the two inhomogeneous media. Its distribution depends on the media properties that define the interface, and the orientation of the coil to this interface [60]. As calculated from equations (12) and (13), the induced surface charge distribution on the air/skin interface was a function of $\theta$

$$
\rho_{A M}(\theta)=-j \omega B_{0} C \frac{R_{B}{ }^{2}\left(S_{M}-S_{B}\right)-R_{M}{ }^{2}\left(S_{M}+S_{B}\right)}{R_{B}{ }^{2}\left(S_{A}-S_{M}\right)\left(S_{M}-S_{B}\right)+R_{M}{ }^{2}\left(S_{A}+S_{M}\right)\left(S_{M}+S_{B}\right)}\left(S_{A} \varepsilon_{M}-S_{M} \varepsilon_{A}\right) \sin \theta
$$


The distribution of the induced surface charges on the muscle/bone interface was also a function of $\theta$

$$
\rho_{M B}(\theta)=2 j \omega B_{0} C \frac{R_{M}{ }^{2} S_{A}}{R_{B}{ }^{2}\left(S_{A}-S_{M}\right)\left(S_{M}-S_{B}\right)+R_{M}{ }^{2}\left(S_{A}+S_{M}\right)\left(S_{M}+S_{B}\right)}\left(S_{M} \varepsilon_{B}-S_{B} \varepsilon_{M}\right) \sin \theta
$$

Charge densities were most prominent at the point where $\theta$ equals to 0 or $180^{\circ}$. At any given instance, the overall pattern of charge distribution on the limb surface and muscle/bone interface were the same, owing to the fact that the same $\sin \theta$ term was present in both equations (19) and (20). When computed with the chosen parameters and a field frequency of $50 \mathrm{~Hz}$, the induced surface charge density was $1.05 \times 10^{-12} \mathrm{C} / \mathrm{m}^{2}$ on the bone/muscle interface. This induced surface charge density was significantly smaller than the densities of the intrinsic surface charges that were carried by proteins on a cell membrane [37]. At $200 \mathrm{kHz}$, the induced surface charge density was $1.1 \times 10^{-5} \mathrm{C} / \mathrm{m}^{2}$ on the bone/muscle interface, comparable to the physiological value or the membrane charges.

\subsection{Compressive normal stress on the bone surface}

Interaction between the induced surface charges and the electric field generated stress

on the bone surface in the radial $\hat{r}$ direction. The stress (force per unit area) generated on an interface was equal to the product of the charge and the average of the electrical field on both sides of the interface $[15,58,59]$. Therefore, normal stress ( $\hat{r}$ direction) on the air/muscle interface (AM) was

$$
P_{r A M}=\frac{B_{0}^{2} C^{2} \omega^{2}\left(S_{A}+S_{M}\right)\left(\varepsilon_{M} S_{A}-\varepsilon_{A} S_{M}\right)\left[R_{B}{ }^{2}\left(S_{M}-S_{B}\right)-R_{M}{ }^{2}\left(S_{M}+S_{B}\right)\right]^{2}}{2\left[R_{B}{ }^{2}\left(S_{A}-S_{M}\right)\left(S_{M}-S_{B}\right)+R_{M}{ }^{2}\left(S_{A}+S_{M}\right)\left(S_{M}+S_{B}\right)\right]^{2}} \sin ^{2} \theta
$$

Normal stress on the muscle/bone interface $(\mathrm{MB})$ was

$$
P_{r M B}=\frac{2 B_{0}^{2} C^{2} \omega^{2} R_{M}{ }^{4} S_{A}^{2}\left(S_{M}+S_{B}\right)\left(\varepsilon_{B} S_{M}-\varepsilon_{M} S_{B}\right)}{\left[R_{B}{ }^{2}\left(S_{A}-S_{M}\right)\left(S_{M}-S_{B}\right)+R_{M}{ }^{2}\left(S_{A}+S_{M}\right)\left(S_{M}+S_{B}\right)\right]^{2}} \sin ^{2} \theta
$$

This stress (Figure 2) compresses the bone on the equator along the direction of the magnetically induced electric field ( $y$-axis). The maximum stress was $1.2 \times 10^{-21} \mathrm{~N} / \mathrm{m}^{2}$ when $\theta=\frac{\pi}{2}, \phi=0(50$ $\mathrm{Hz})$.

Orientation of the magnetic coil plays significant roles in electromagnetic stimulation. There are two parameters that define the orientation of the coil to the bone. The distance between the center of the coil and the bone $(\mathrm{C})$ determined the magnitude of the induced electric current, and the normal stress (Figure 3). A larger $C$ value is associated with a greater intensity of the induced electric field. The pattern of stress distribution is a function of $\sin \theta$, where $\theta$ is defined by the relative positioning of the bone to the coil.

Bone size varies among patients of different age, gender, and pathological conditions. Figure 4 plots the angular dependency of the normal stress at various bone radii. Larger bone is associated with greater normal stress.

The frequency of the externally-applied magnetic field determines the strength of the induced field by the law of electromagnetic induction [54]. Figure 5 illustrates the normal stress generated by magnetic fields with $50 \mathrm{~Hz}, 2 \mathrm{~K} \mathrm{~Hz}$, and $200 \mathrm{~K} \mathrm{~Hz}$, respectively. Higher frequency fields generated larger normal stress. 


\subsection{Shear stress on the bone surface}

Shear stress is defined as the component of stress coplanar with a material cross section. Shear stress arises from the force vector component parallel to the cross section. On the bone surface, the shear stress generated by the time-varying magnetic field is

$$
P_{\theta U B}=-B_{0}^{2} C R_{M}{ }^{2} \omega^{2} S_{A}\left(\varepsilon_{B} S_{M}-\varepsilon_{M} S_{B}\right) \frac{R_{B}\left[R_{B}{ }^{2}\left(S_{A}-S_{M}\right)\left(S_{M}-S_{B}\right)+R_{M}{ }^{2}\left(S_{A}+S_{M}\right)\left(S_{M}+S_{B}\right)\right]-4 C R_{M}{ }^{2} S_{A} S_{M} \cos \theta}{\left[R_{B}{ }^{2}\left(S_{A}-S_{M}\right)\left(S_{M}-S_{B}\right)+R_{M}{ }^{2}\left(S_{A}+S_{M}\right)\left(S_{M}+S_{B}\right)\right]^{2}} \sin \theta
$$

Figure 6 plots the shear stress on the bone surface under magnetic field stimulation. The maximal shear stress is located at $\theta=\frac{\pi}{2}, \phi=0$. Obviously, asymmetric distribution of the induced electric field around the bone ensures the shear stress to be non-zero. The shear stress was significantly greater than the compressing stress. The maximally calculated shear stress was $1.2 \times 10^{-11} \mathrm{~N} / \mathrm{m}^{2}$. This result suggests that shear stress is probably a dominant factor that affects bone biomechanics in magnetic stimulation. Magnitude of the shear stress is dependent on the orientation of the bone to the coil (Figure 7), bone size (Figure 8) and frequency of the magnetic field (Figure 9). An increment in the born-coil center distance, bone size, or field frequency can cause greater shear stress on the bone.

\section{Discussion}

This paper performed three-dimensional modeling of bone biomechanics under a timevarying electromagnetic field. It provided the first analytical expressions for normal stress and shear stress generated on the bone surface by the field. Both normal and shear stress depend on the geometrical and electric properties of the bone and its surrounding tissue. They are also dependent on the properties of the magnetic field and the orientation of the magnetic coil. Shear stress is quantitatively greater than the compressive, normal stress. Under low frequency stimulation, the stress generated on the bone could be trivial at low field frequency, but significant at higher frequencies. Alteration of bone mechanics by the electromagnetic field could provide a mechanistic explanation of the biological benefits that an EM field would apply to fractured bones.

\subsection{Impact of coil orientation to the magnetically-generated mechanical stresses}

The normal stress and shear stress are both functions of the magnetic field parameters. Previously, there has been mounting evidence that the effects of electromagnetic stimulation depend on the orientation of the stimuli to the biological target. This evidence primarily emerged in the field of bioelectricity, in which the external field affects cellular or tissue's intrinsic bipotential. For example, at the cellular level, neurons in the motor cortex displayed different sensitivities to transcranial magnetic fields with differing coil orientations and shapes $[10,39,4,28,49,20]$. Transmembrane potential in a cell under point electrode stimulation is dependent on the electrode-to-cell distance [34]. The threshold for excitation of the retinal ganglion cell axons is a function of the orientation of the electric field to the axons [16]. It was then proved that the amplitude and pattern of membrane potential within the cell was dependent on its orientation to the externally-applied field [23,24]. At gross tissue level, orientation of the electrodes plays a significant role in determining the outcome of tumor electrochemotherapy [52]. In the clinical practice of transcranial magnetic stimulation (TMS) of the motor cortex, orientation of the magnetic coil is a major concern in the outcome $[10,20,49]$.

Our results, from the biomechanical perspective, provide further evidence that the impact of magnetic field on biological tissue is dependent on the coil location, including orientation of the bone (Figure 2 and Figure 6) and its distance to the coil (Figure 3 and Figure 7). The difference in the bone orientations to the coil determines the pattern of mechanical stress distribution on the 
bone surface, and the bone-coil distance determines the intensity of the induced electric field, surface charge density, and therefore, the normal and shear stresses generated on the bone surface. Therefore, this biomechanics work further supports the notion that the efficacy of EM stimulation is a consequence of optimization of the stimulation orientation [60]. Care should be taken in the design and orientation of the magnetic coil in electromagnetic aided therapy for bone fracture patients.

\subsection{Significance of high frequency stimulation}

The easiest way to increase mechanical stress under magnetic stimulation is to increase the field frequency via electromagnetic induction, since both the induced electric fields (equation 16-18) and the surface charges (equations 19 and 20) are proportional to the field frequency. This frequency dependency is more predominant in the expression of the normal stress (equation 22) and shear stress (equation 23), since both stresses are proportional to the square of the field frequency. These results also suggest that if a magnetic stimuli contains many frequency components (such as high harmonic frequency contained in square pulses), then the mechanical impact could be more likely induced by these high frequency components.

\subsection{Impact of tissue properties on magnetically-generated mechanical stresses}

The normal stress and shear stress are also functions of the properties of the targeted bone tissue. Although previous work has suggested that tissue properties could play important roles in the outcomes of the stimulation [23], much of the evidence that supports this notion, again, emerged from the analysis of bioelectricities under EM stimulation. For example, larger cells are associated with greater induced transmission potential under magnetic field stimulation [56], and require lower external fields to create permeable cell membranes [13].

Both the geometrical properties of the bone and its electric properties contribute to the mechanical stress. The magnitude of the normal stress (Figure 4) and shear stress (Figure 8) are functions of bone size. In addition, electric properties of the bone and the muscle, also affect electric field and charge distribution, and ultimately, mechanical stress. Our results further extended our understanding of the interaction between the magnetic field and the biological tissue, and provide strong biomechanical evidence that tissue properties interact with the external field in generating biological effects, a hypothesis that has been elaborated in greater details in our recent work [60].

The normal stress is significantly smaller in comparison with the shear stress, suggesting that EM-aided treatment for fractures could be due to the shear stress imposed on the bone. It will be interesting to test this model prediction by adding additional normal mechanical stress on the bone, while a magnetic stimulation protocol is implemented. If the model predication is correct, then adding such stress would provide minimal benefit to bone recovery. There are some reports showing that external application of cyclic tensile strains does not effectively enhance bone healing [3].

\subsection{Possible cellular mechanotransduction in the magnetic field}

The fact that a time-varying magnetic field can impose mechanical stress on the bone surface, in normal and shear directions, respectively, indicates that cells that sense mechanical load could be activated and respond to the magnetic fields. Bone cells respond directly or indirectly to the strains applied on them by external loading, a process called mechanotransduction, which translates the physical stimulus into biological responses. Mechanotransduction involves numerous signal transduction pathway. Mechanical strain can be sensed by the bone lining cells and osteocytes, which act as sensors of local bone strain [36]. Bone lining cells that cover the bone surface are capable of regulating adaption as osteocytes. In 
vitro experiments have demonstrated that when cells experience stretching stress, a series of responses can be observed. For example, dynamic cell stretching increases human osteoblast proliferation and CICP synthesis but decreases osteocalcin synthesis and alkaline phosphatase activity [21]. A cell culture experiment demonstrated that dynamic cell stretching stimulated human primary osteoblast proliferation [40]. Static mechanical stress on rat osteoblasts seeded three-dimensionally in collagen scaffolds promoted the expression of alkaline phosphatase and osteocalcin, a marker for osteoblastic differentiation [2]. It should be recognized that even a tiny deformation of the cell membrane could impose significant impact on intracellular signaling [14], mainly in the mechanotransduction signaling pathways [53].

The molecular alteration induced by this magnetically-generated mechanical load is unknown, but can be speculated. Previous studies have indicated that mechanical loading could lead to direct signal transduction. For example, mechanical loading could lead to the direct activation of osteoblasts, which react with an increased expression of matrix proteins [55] and growth factors [22]. Integrins are believed to be the mechanoreceptors of the physical stimuli [19]. Cadherins, which link cytoskeletons of neighboring cells, are also involved in mechanical signal transduction [11]. It will be interesting to investigate if magnetic field-induced mechanical stress will affect these proteins.

\subsection{Model limits and further work}

This model treats the bone as a homogeneous conductive body with a cylindrical shape. Future models shall consider the inhomogeneity of the bone, including its irregular shape and conductive properties. For example, the resistivity of bone is three to four times greater in the radial direction than for the longitudinal direction [6]. This model does not consider the spatial decay of the magnetic field, and assumes it to be homogeneous in the modeled area. Future work shall also consider more detailed bone geometry with a numerical approach. Nevertheless, the biomechanical analysis performed by this three-dimensional model is valuable, especially as it would provide benchmarks for the validation of more general numerical solution to such problems.

\section{Appendix - Determining unknown coefficients $C_{n}, D_{n}$ in equation (3) using \\ boundary conditions (A)-(D)}

Since $V$ is bounded at $r=0$ and $r \rightarrow \infty$, from equation (3),

$$
D_{A}=0 \quad A_{B}=0
$$

Therefore, expressions for the potential distribution in the extracellular media, the membrane, and in the cytoplasm are:

$$
\begin{aligned}
& V_{A}=\frac{A_{A}}{r} \sin \theta \quad(\mathrm{A}-1) \\
& V_{M}=\left(\frac{A_{M}}{r}+D_{M} r\right) \sin \theta \\
& V_{B}=D_{B} r \sin \theta \quad(\mathrm{A}-3)
\end{aligned}
$$

Substitution of $A_{0 r}$ (equation 9) and the $\vec{r}$ components of $\nabla V$ in the three regions into (1) yielded the expressions of the normal components of the electric fields in the three regions: 
$E_{A r}=-\frac{j \omega B_{0} C}{2} \sin \theta+\frac{A_{A}}{r^{2}} \sin \theta$

$E_{M r}=-\frac{j \omega B_{0} C}{2} \sin \theta+\left(\frac{A_{M}}{r^{2}}-D_{M}\right) \sin \theta$

$E_{B r}=-\frac{j \omega B_{0} C}{2} \sin \theta-D_{B} \sin \theta$

Following boundary condition (A), $V$ is continuous at the air/limb interface $\left(r=R_{M}\right)$ and muscle/bone interface $\left(r=R_{B}\right)$,

$\frac{A_{A}}{R_{M}}=\frac{A_{M}}{R_{M}}+D_{M} R_{M}$

$\frac{A_{M}}{R_{B}}+D_{M} R_{B}=D_{B} R_{B}$

From the boundary condition (B), that the normal components of the current densities are continuous between two different media (equation 1 and 2), we can obtain the following equations:

$S_{A}\left(-\frac{j \omega B_{0} C}{2}+\frac{A_{A}}{R_{M}^{2}}\right)=S_{M}\left(-\frac{j \omega B_{0} C}{2}+\frac{A_{M}}{R_{M}^{2}}-D_{M}\right)$
$S_{M}\left(-\frac{j \omega B_{0} C}{2}+\frac{A_{M}}{R_{B}^{2}}-D_{M}\right)=S_{B}\left(-\frac{j \omega B_{0} C}{2}-D_{B}\right)$

Equations $(\mathrm{A}-7)$ through $(\mathrm{A}-10)$ yielded the last four unknown coefficients:

$$
\begin{aligned}
& A_{A}=\frac{j \omega B_{0} C}{2} \frac{R_{M}^{2}\left[\left(S_{A}+S_{M}\right)\left(S_{M}-S_{D}\right) R_{B}^{2}+\left(S_{A}-S_{M}\right)\left(S_{M}+S_{B}\right) R_{M}^{2}\right]}{\left(S_{A}-S_{M}\right)\left(S_{M}-S_{B}\right) R_{B}^{2}+\left(S_{A}+S_{M}\right)\left(S_{M}+S_{B}\right) R_{M}^{2}} \\
& A_{M}=\frac{j \omega B_{0} C}{2} \frac{2 R_{B}^{2} R_{M}^{2} S_{A}\left(S_{M}-S_{B}\right)}{\left(S_{A}-S_{M}\right)\left(S_{M}-S_{B}\right) R_{B}^{2}+\left(S_{A}+S_{M}\right)\left(S_{M}+S_{B}\right) R_{M}^{2}} \\
& D_{M}=-\frac{j \omega B_{0} C}{2} \frac{\left(S_{A}-S_{M}\right)\left[\left(S_{M}-S_{B}\right) R_{B}^{2}-\left(S_{M}+S_{B}\right) R_{M}^{2}\right]}{\left(S_{A}-S_{M}\right)\left(S_{M}-S_{B}\right) R_{B}^{2}+\left(S_{A}+S_{M}\right)\left(S_{M}+S_{B}\right) R_{M}^{2}} \\
& D_{B}=-\frac{j \omega B_{0} C}{2} \frac{\left(S_{A}-S_{M}\right)\left(S_{M}-S_{B}\right) R_{B}^{2}+\left[S_{A}\left(S_{B}-3 S_{M}\right)+S_{M}\left(S_{M}+S_{B}\right)\right] R_{M}^{2}}{\left(S_{A}-S_{M}\right)\left(S_{M}-S_{B}\right) R_{B}^{2}+\left(S_{A}+S_{M}\right)\left(S_{M}+S_{B}\right) R_{M}^{2}}
\end{aligned}
$$

\section{List of abbreviations}

$B_{o}$ - Intensity of the time-varying magnetic field (Tesla)

$\omega$ - Angular frequency of the time-varying magnetic field (radians/s). 
$E_{A}$ - Intensity of the electric field induced by the time-varying magnetic field in the air $(\mathrm{V} / \mathrm{m})$

$E_{M}$ - Intensity of the electric field induced by the time-varying magnetic field in the muscle $(\mathrm{V} / \mathrm{m})$

$E_{B}$ - Intensity of the electric field induced by the time-varying magnetic field in the bone $(\mathrm{V} / \mathrm{m})$

$\rho_{A M}$ - Surface charge density on the air/muscle interface $\left(\mathrm{C} / \mathrm{m}^{2}\right)$

$\rho_{M B}$ - Surface charge density on the muscle/bone interface $\left(\mathrm{C} / \mathrm{m}^{2}\right)$

$P_{r A M}$ - Normal stress on the air/muscle interface $\left(\mathrm{N} / \mathrm{m}^{2}\right)$

$P_{r M B}$ - Normal stress on the muscle/bone interface $\left(\mathrm{N} / \mathrm{m}^{2}\right)$

$P_{\theta A M}$ - Sheer stress on the air/muscle interface $\left(\mathrm{N} / \mathrm{m}^{2}\right)$

$P_{\theta M B}$ - Sheer stress on the muscle/bone interface $\left(\mathrm{N} / \mathrm{m}^{2}\right)$

$R_{M}$ - Radius of the arm (m)

$R_{B}$ - Radius of the bone $(\mathrm{m})$

\section{Acknowledgements}

Austin Curcuru helped with the validation of the equations and Stephanie Kaszuba assisted with editing of the manuscript.

\section{Figure Titles and Legends}

Fig.1. Model setup for limb stimulation by a time-varying EM magnetic field. A. The magnetic coil and the limb. B. A co-centric muscle/bone model in the EM field. C. A cylindrical coordinate system that defines the orientation of the magnetic field and the limb.

Fig.2. Compressive stress distribution on the bone under a time-varying magnetic field. The stress is normal to the bone surface. Orientation of the muscle/bone and the coil were depicted on the right $\left(\mathrm{C}=10 \mathrm{~cm}\right.$ and $\left.\mathrm{R}_{\mathrm{B}}=2.5 \mathrm{~cm}\right)$.

Fig.3. Angular distribution of the normal stress, and its dependency on distance C. A. Linear plot. B. Log plot. $\mathrm{C}=2.5 \mathrm{~cm}$ (blue); $\mathrm{C}=10 \mathrm{~cm}$ (black); $\mathrm{C}=20 \mathrm{~cm}$ (red).

Fig.4. Angular distribution of the radial stress and its dependency on bone size $\left(R_{B}\right)$. Bone size is $1.5 \mathrm{~cm}$ (blue), $2.5 \mathrm{~cm}$ (black) and $4.5 \mathrm{~cm}$ (red), respectively. $\mathrm{C}=10 \mathrm{~cm}$ in these plots.

Fig.5. Angular distribution of the radial stress and its dependency on field frequency $(50 \mathrm{~Hz}-\mathrm{black}$, $2 \mathrm{KHz}$-red, and $200 \mathrm{KHz}-$ green). In this plot, $\mathrm{C}=10 \mathrm{~cm}$ and $\mathrm{R}_{\mathrm{B}}=2.5 \mathrm{~cm}$.

Fig.6.Shear stress distribution on the born surface under a time-varying magnetic field stimulation. The shear stress is calculated when $\mathrm{C}=10 \mathrm{~cm}$ and $R_{B}=2.5 \mathrm{~cm}$.

Fig.7. Angular distribution of the shear stress and its dependency on coil location C. A. Linear plot. B. Log plot. $\mathrm{C}=2.5 \mathrm{~cm}$ (blue); $\mathrm{C}=10 \mathrm{~cm}$ (black); $\mathrm{C}=20 \mathrm{~cm}$ (red).

Fig.8. Angular distribution of the shear stress and its dependency on the bone size $\left(\mathrm{R}_{\mathrm{B}}\right)$. Bone size is $1.5 \mathrm{~cm}$ (blue), $2.5 \mathrm{~cm}$ (black) and $4.5 \mathrm{~cm}$ (red), respectively. $\mathrm{C}=10 \mathrm{~cm}$ in these plots.

Fig.9. Angular distribution of the shear stress and its dependency on field frequency $(50 \mathrm{~Hz}-b$ lack, $2 \mathrm{KHz}$-red, and $200 \mathrm{KHz}$-green). In this plot, $\mathrm{C}=10 \mathrm{~cm}$ and $\mathrm{R}_{\mathrm{B}}=2.5 \mathrm{~cm}$. 
1. Aaron RK, Ciombor DM, Simon BJ (2004) Treatment of nonunions with electric and electromagnetic fields. Clinical orthopaedics and related research (419):21-29

2. Akhouayri O, Lafage-Proust MH, Rattner A, Laroche N, Caillot-Augusseau A, Alexandre C, Vico L (1999) Effects of static or dynamic mechanical stresses on osteoblast phenotype expression in threedimensional contractile collagen gels. Journal of cellular biochemistry 76 (2):217-230

3. Augat $P$, Merk J, Wolf S, Claes L (2001) Mechanical stimulation by external application of cyclic tensile strains does not effectively enhance bone healing. Journal of orthopaedic trauma 15 (1):54-60

4. Bashir S, Perez JM, Horvath JC, Pascual-Leone A (2013) Differentiation of motor cortical representation of hand muscles by navigated mapping of optimal TMS current directions in healthy subjects. Journal of clinical neurophysiology : official publication of the American Electroencephalographic Society 30 (4):390-395. doi:10.1097/WNP.0b013e31829dda6b

5. Carter DR, Beaupre GS, Giori NJ, Helms JA (1998) Mechanobiology of skeletal regeneration. Clinical orthopaedics and related research (355 Suppl):S41-55

6. Chakkalakal DA, Johnson MW, Harper RA, Katz JL (1980) Dielectric properties of fluid-saturated bone. IEEE transactions on bio-medical engineering 27 (2):95-100

7. Ciombor DM, Aaron RK (2005) The role of electrical stimulation in bone repair. Foot and ankle clinics 10 (4):579-593, vii. doi:10.1016/j.fcl.2005.06.006

8. Claes LE, Heigele CA (1999) Magnitudes of local stress and strain along bony surfaces predict the course and type of fracture healing. Journal of biomechanics 32 (3):255-266

9. The classic: Fundamental aspects of fracture treatment by Iwao Yasuda, reprinted from J. Kyoto Med. Soc., 4:395-406, 1953 (1977). Clinical orthopaedics and related research (124):5-8

10. Di Lazzaro V, Oliviero A, Pilato F, Saturno E, Dileone M, Mazzone P, Insola A, Tonali PA, Rothwell JC (2004) The physiological basis of transcranial motor cortex stimulation in conscious humans. Clinical neurophysiology : official journal of the International Federation of Clinical Neurophysiology 115 (2):255-266. doi:S1388245703003638 [pii]

11. Di Palma F, Chamson A, Lafage-Proust MH, Jouffray P, Sabido O, Peyroche S, Vico L, Rattner A (2004) Physiological strains remodel extracellular matrix and cell-cell adhesion in osteoblastic cells cultured on alumina-coated titanium alloy. Biomaterials 25 (13):2565-2575

12. Frost HM (1987) Bone "mass" and the "mechanostat": a proposal. The Anatomical record 219 (1):19. doi:10.1002/ar.1092190104

13. Gehl J (2003) Electroporation: theory and methods, perspectives for drug delivery, gene therapy and research. Acta physiologica Scandinavica 177 (4):437-447

14. Goldenberg NM, Steinberg BE (2010) Surface charge: a key determinant of protein localization and function. Cancer research 70 (4):1277-1280. doi:10.1158/0008-5472.CAN-09-2905

15. Griffiths DJ (1999) Introduction to Electrodynamics, 3rd ed.

16. Grumet AE, Wyatt JL, Jr., Rizzo JF, 3rd (2000) Multi-electrode stimulation and recording in the isolated retina. Journal of neuroscience methods 101 (1):31-42. doi:S0165-0270(00)00246-6 [pii]

17. Hannouche D, Petite $H$, Sedel $L$ (2001) Current trends in the enhancement of fracture healing. The Journal of bone and joint surgery British volume 83 (2):157-164

18. Huang C, Ogawa R (2010) Mechanotransduction in bone repair and regeneration. FASEB journal : official publication of the Federation of American Societies for Experimental Biology 24 (10):3625-3632. doi:10.1096/fj.10-157370

19. Ingber D (1991) Integrins as mechanochemical transducers. Current opinion in cell biology 3 (5):841848

20. Janssen AM, Oostendorp TF, Stegeman DF (2015) The coil orientation dependency of the electric field induced by TMS for M1 and other brain areas. Journal of neuroengineering and rehabilitation 12:47. doi:10.1186/s12984-015-0036-2 
21. Kaspar D, Seidl W, Neidlinger-Wilke C, Ignatius A, Claes L (2000) Dynamic cell stretching increases human osteoblast proliferation and CICP synthesis but decreases osteocalcin synthesis and alkaline phosphatase activity. Journal of biomechanics 33 (1):45-51

22. Kawata A, Mikuni-Takagaki Y (1998) Mechanotransduction in stretched osteocytes--temporal expression of immediate early and other genes. Biochemical and biophysical research communications 246 (2):404-408. doi:10.1006/bbrc.1998.8632

23. Kotnik T, Bobanovic F, Miklavcic D (1997) Sensitivity of Transmembrane Voltage Induced by Applied Electric Fields-A Theoretical Analysis. Bioelectrochem Bioenerg 43 (2):285-291

24. Kotnik T, Miklavcic D (2000) Analytical description of transmembrane voltage induced by electric fields on spheroidal cells. Biophysical journal 79 (2):670-679. doi:S0006-3495(00)76325-9 [pii]

$10.1016 / \mathrm{S} 0006-3495(00) 76325-9$

25. Kotnik T, Miklavcic D (2000) Second-order model of membrane electric field induced by alternating external electric fields. IEEE Trans Biomed Eng 47 (8):1074-1081. doi:10.1109/10.855935

26. Kotnik T, Miklavcic D, Slivnik T (1998) Time course of transmembrane voltage induced by timevarying electric field - a method for theoretical analysis and its application. Bioelectrochem Bioenerg 45:3-16

27. Krasteva VT, Papazov SP, Daskalov IK (2003) Peripheral nerve magnetic stimulation: influence of tissue non-homogeneity. Biomed Eng Online 2:19. doi:10.1186/1475-925X-2-19

1475-925X-2-19 [pii]

28. Laakso I, Hirata A, Ugawa Y (2014) Effects of coil orientation on the electric field induced by TMS over the hand motor area. Physics in medicine and biology 59 (1):203-218. doi:10.1088/0031$9155 / 59 / 1 / 203$

29. Lacroix D, Prendergast PJ (2002) A mechano-regulation model for tissue differentiation during fracture healing: analysis of gap size and loading. Journal of biomechanics 35 (9):1163-1171

30. Lacroix D, Prendergast PJ, Li G, Marsh D (2002) Biomechanical model to simulate tissue differentiation and bone regeneration: application to fracture healing. Medical \& biological engineering \& computing 40 (1):14-21

31. Larsson S, Kim W, Caja VL, Egger EL, Inoue N, Chao EY (2001) Effect of early axial dynamization on tibial bone healing: a study in dogs. Clinical orthopaedics and related research (388):240-251

32. LeBlanc A, Shackelford L, Schneider V (1998) Future human bone research in space. Bone 22 (5 Suppl):113S-116S

33. Leblanc AD, Schneider VS, Evans HJ, Engelbretson DA, Krebs JM (1990) Bone mineral loss and recovery after 17 weeks of bed rest. Journal of bone and mineral research : the official journal of the American Society for Bone and Mineral Research 5 (8):843-850. doi:10.1002/jbmr.5650050807

34. Lee DC, Grill WM (2005) Polarization of a spherical cell in a nonuniform extracellular electric field. Annals of biomedical engineering 33 (5):603-615

35. LG Aslamazov and AA Varlamov (2001) The Wonder of Physics.

36. Liedert A, Kaspar D, Augat P, Ignatius A, Claes L (2005) Mechanobiology of Bone Tissue and Bone Cells. In: Kamkin A, Kiseleva I (eds) Mechanosensitivity in Cells and Tissues. Moscow,

37. Lipman KM, Dodelson R, Hays RM (1966) The surface charge of isolated toad bladder epithelial cells. Mobility, effect of pH and divalent ions. J Gen Physiol 49 (3):501-516

38. Mansfield P, Harvey PR (1993) Limits to neural stimulation in echo-planar imaging. Magn Reson Med $29(6): 746-758$

39. Mills KR, Boniface SJ, Schubert M (1992) Magnetic brain stimulation with a double coil: the importance of coil orientation. Electroencephalography and clinical neurophysiology 85 (1):1721 
40. Neidlinger-Wilke C, Wilke HJ, Claes L (1994) Cyclic stretching of human osteoblasts affects proliferation and metabolism: a new experimental method and its application. Journal of orthopaedic research : official publication of the Orthopaedic Research Society 12 (1):70-78. doi:10.1002/jor.1100120109

41. Nelson S (2015) Dielectric Properties of Agricultural materials and their Applications.

42. Pauwels F (1976) Biomechanics of the Normal and Diseased Hip. Theoretical Foundation, Technique and Results of Treatment. An Atlas. . Springer-Verlag, Berlin, Heidelberg, New York

43. Polk C, Song JH (1990) Electric fields induced by low frequency magnetic fields in inhomogeneous biological structures that are surrounded by an electric insulator. Bioelectromagnetics 11 (3):235-249

44. Prendergast PJ, Huiskes R, Soballe K (1997) ESB Research Award 1996. Biophysical stimuli on cells during tissue differentiation at implant interfaces. Journal of biomechanics 30 (6):539-548

45. Roderic S. Lakes RAHaJLK (1977) Dielectric relaxation in cortical bone J Appl Phys 48 (2)

46. Ruohonen J, Panizza M, Nilsson J, Ravazzani P, Grandori F, Tognola G (1996) Transverse-field activation mechanism in magnetic stimulation of peripheral nerves. Electroencephalogr Clin Neurophysiol 101 (2):167-174

47. Ryder KD, Duncan RL (2001) Parathyroid hormone enhances fluid shear-induced [Ca2+]i signaling in osteoblastic cells through activation of mechanosensitive and voltage-sensitive Ca2+ channels. Journal of bone and mineral research : the official journal of the American Society for Bone and Mineral Research 16 (2):240-248. doi:10.1359/jbmr.2001.16.2.240

48. S. D. Pawar PM, D. M. Lal (2009) Effect of relative humidity and sea level pressure on electrical conductivity of air over Indian Ocean. Journal of Geophysical Research 114 (D02205). doi:doi:10.1029/2007JD009716

49. Salvador R, Silva S, Basser PJ, Miranda PC (2011) Determining which mechanisms lead to activation in the motor cortex: a modeling study of transcranial magnetic stimulation using realistic stimulus waveforms and sulcal geometry. Clinical neurophysiology : official journal of the International Federation of Clinical Neurophysiology 122 (4):748-758. doi:10.1016/j.clinph.2010.09.022

50. Sarmiento A, McKellop HA, Llinas A, Park SH, Lu B, Stetson W, Rao R (1996) Effect of loading and fracture motions on diaphyseal tibial fractures. Journal of orthopaedic research : official publication of the Orthopaedic Research Society 14 (1):80-84. doi:10.1002/jor.1100140114

51. Schultz LGHaHL (1936) The Dielectric Constant of Air at Radiofrequencies. Physics 7:133-136. doi:10.1063/1.1745374.

52. Semrov D, Miklavcic D (1998) Calculation of the electrical parameters in electrochemotherapy of solid tumours in mice. Comput Biol Med 28 (4):439-448

53. Sniadecki NJ (2010) A tiny touch: activation of cell signaling pathways with magnetic nanoparticles. Endocrinology 151 (2):451-457. doi:10.1210/en.2009-0932

54. Stratton J (1941) Electromagnetic Theory. McGraw-Hill, New York

55. Toma CD, Ashkar S, Gray ML, Schaffer JL, Gerstenfeld LC (1997) Signal transduction of mechanical stimuli is dependent on microfilament integrity: identification of osteopontin as a mechanically induced gene in osteoblasts. Journal of bone and mineral research : the official journal of the American Society for Bone and Mineral Research 12 (10):1626-1636. doi:10.1359/jbmr.1997.12.10.1626

56. Ye H, Cotic M, Carlen PL (2007) Transmembrane potential induced in a spherical cell model under low-frequency magnetic stimulation. Journal of neural engineering 4 (3):283-293. doi:10.1088/1741-2560/4/3/014

57. Ye H, Cotic M, Fehlings MG, Carlen PL (2011) Transmembrane potential generated by a magnetically induced transverse electric field in a cylindrical axonal model. Medical \& biological engineering \& computing 49 (1):107-119. doi:10.1007/s11517-010-0704-0 
58. Ye H, Curcuru A (2015) Vesicle biomechanics in a time-varying magnetic field. BMC biophysics 8 (1):2. doi:10.1186/s13628-014-0016-0

59. Ye H, Curcuru A (2016) Biomechanics of cell membrane under low-frequency time-varying magnetic field: a shell model. Medical \& biological engineering \& computing 54 (12):1871-1881. doi:10.1007/s11517-016-1478-9

60. Ye H, Steiger A (2015) Neuron matters: electric activation of neuronal tissue is dependent on the interaction between the neuron and the electric field. Journal of neuroengineering and rehabilitation 12:65. doi:10.1186/s12984-015-0061-1

61. Yonemori K, Matsunaga S, Ishidou Y, Maeda S, Yoshida H (1996) Early effects of electrical stimulation on osteogenesis. Bone 19 (2):173-180 
A

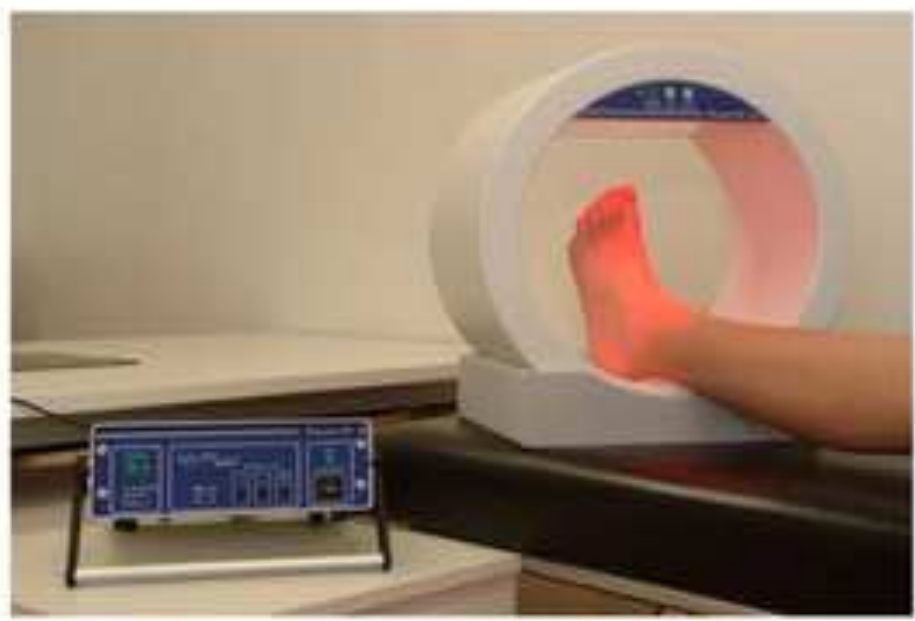

B

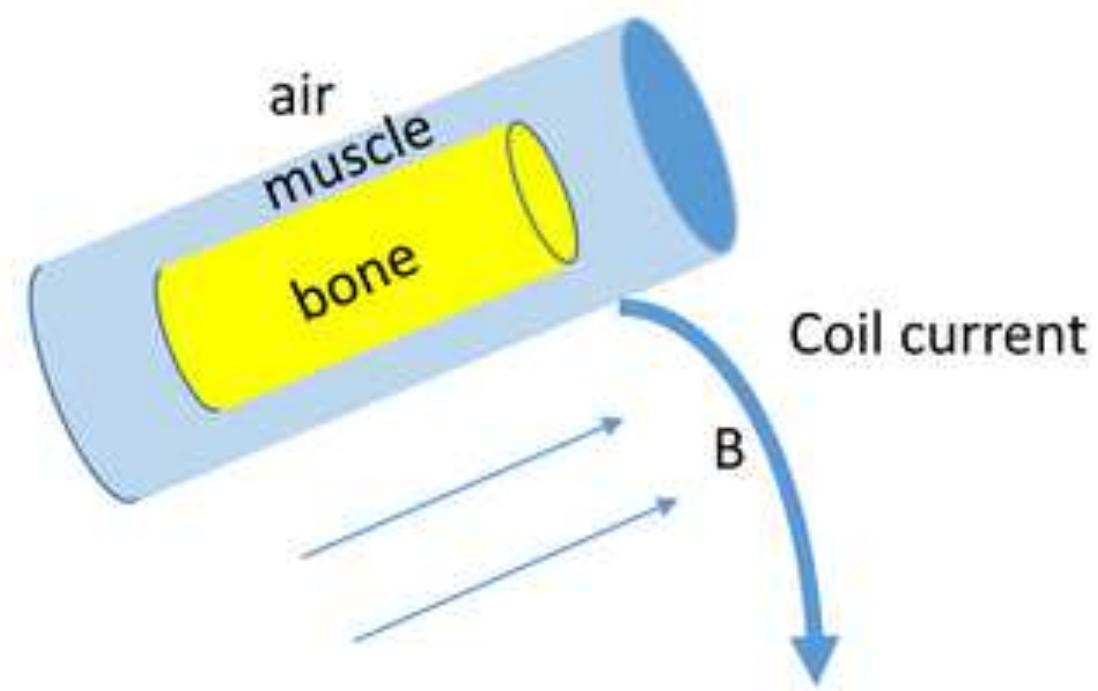

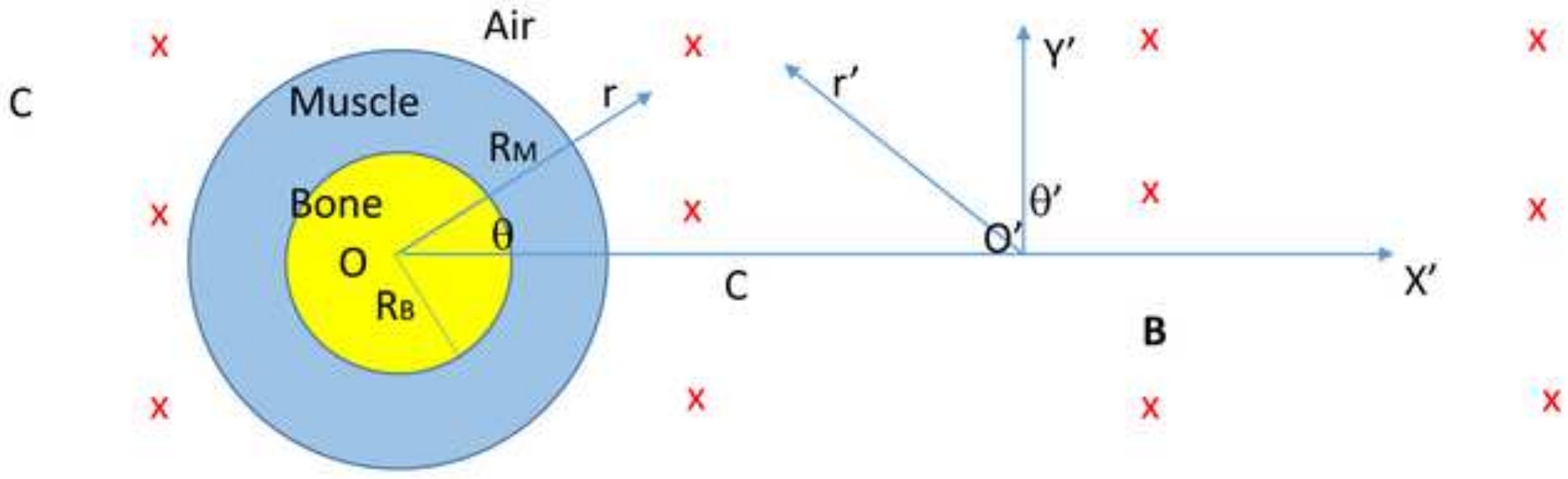



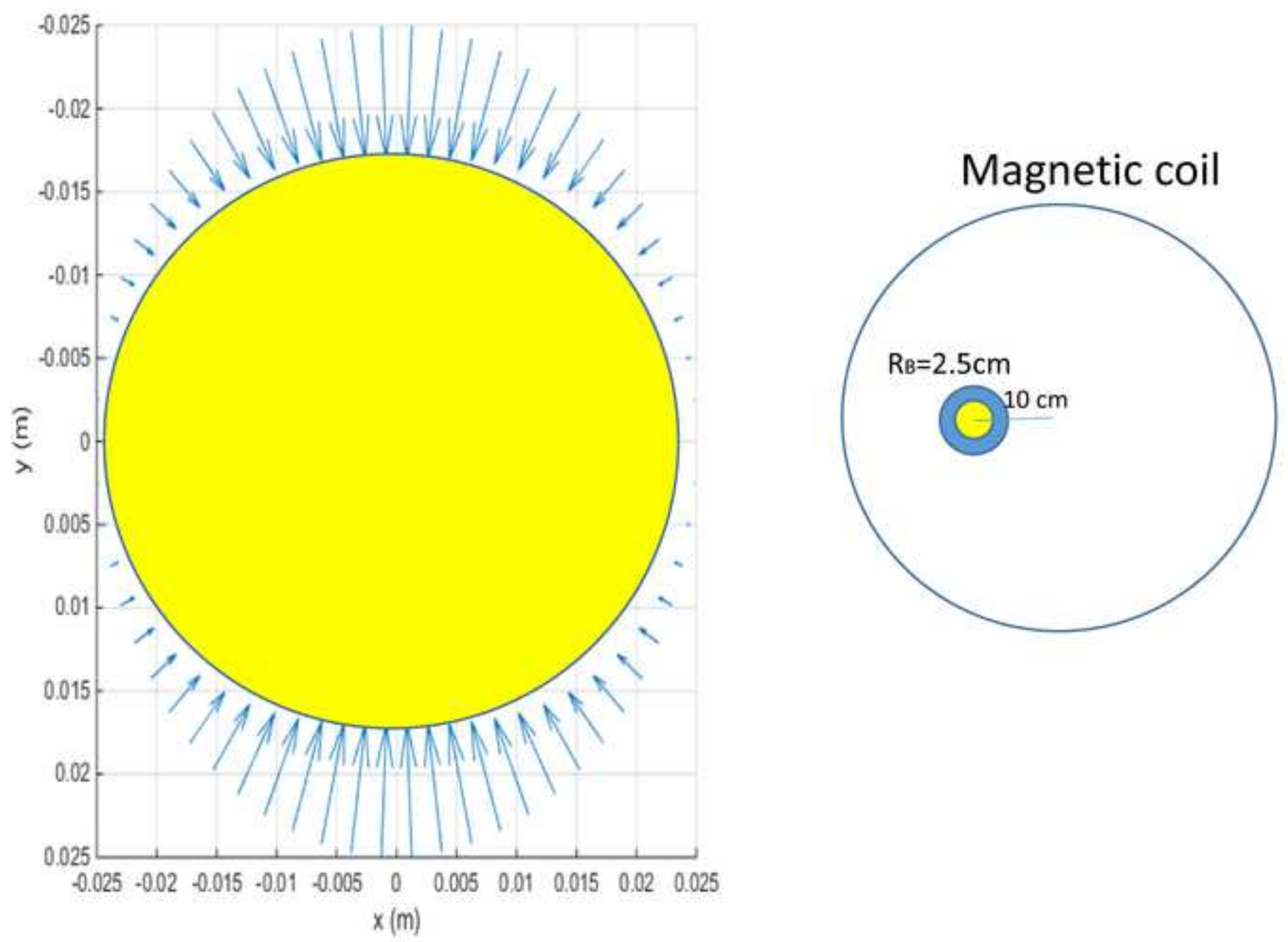

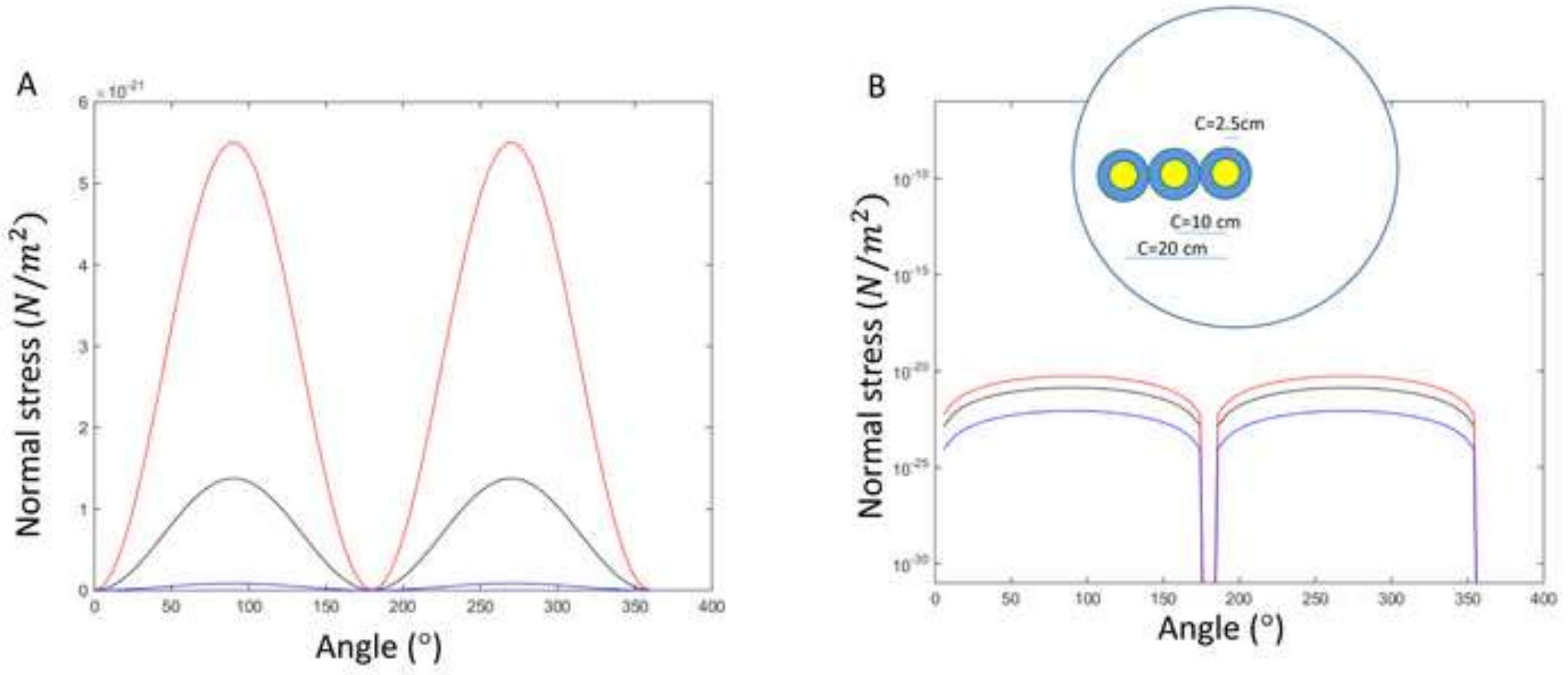

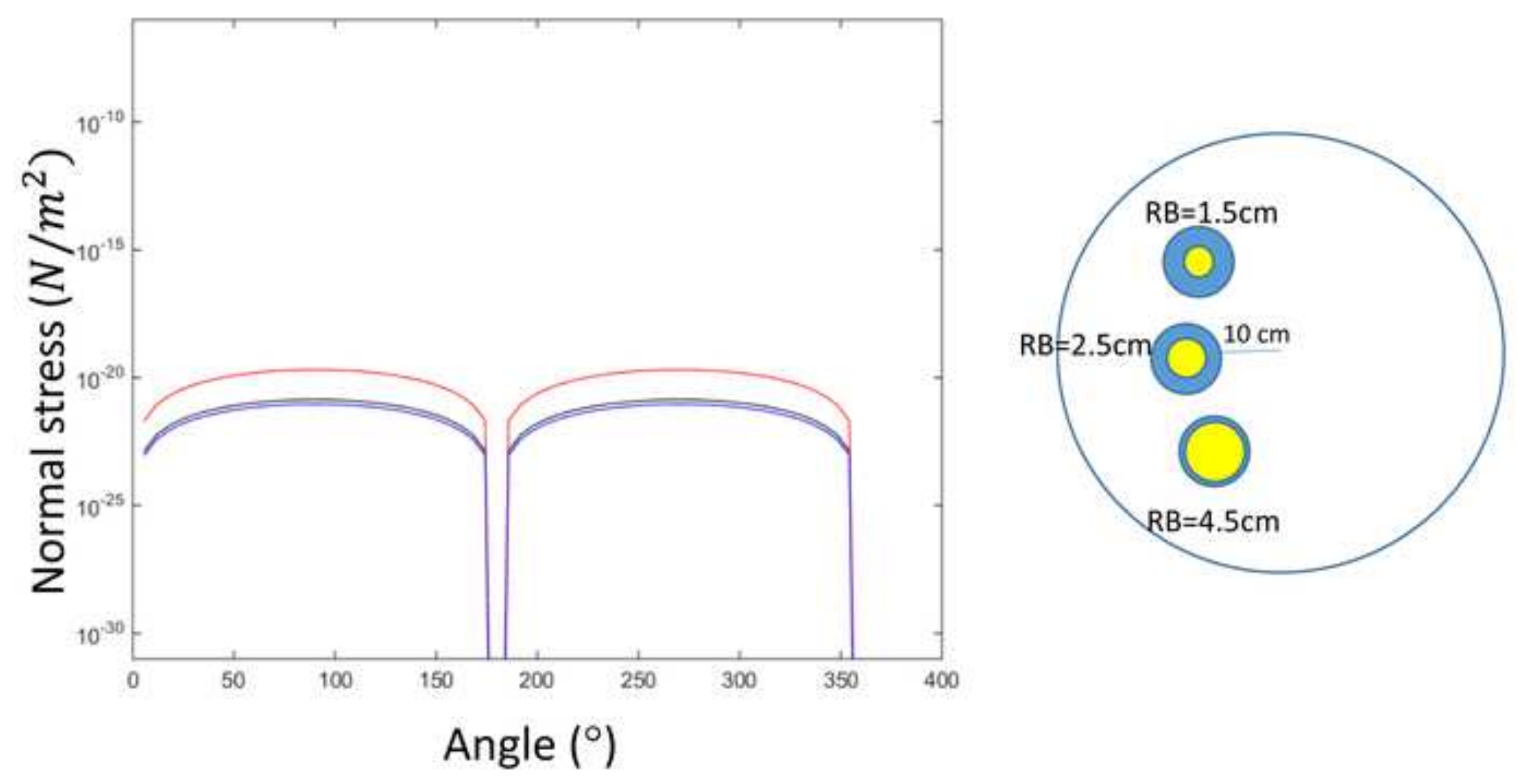

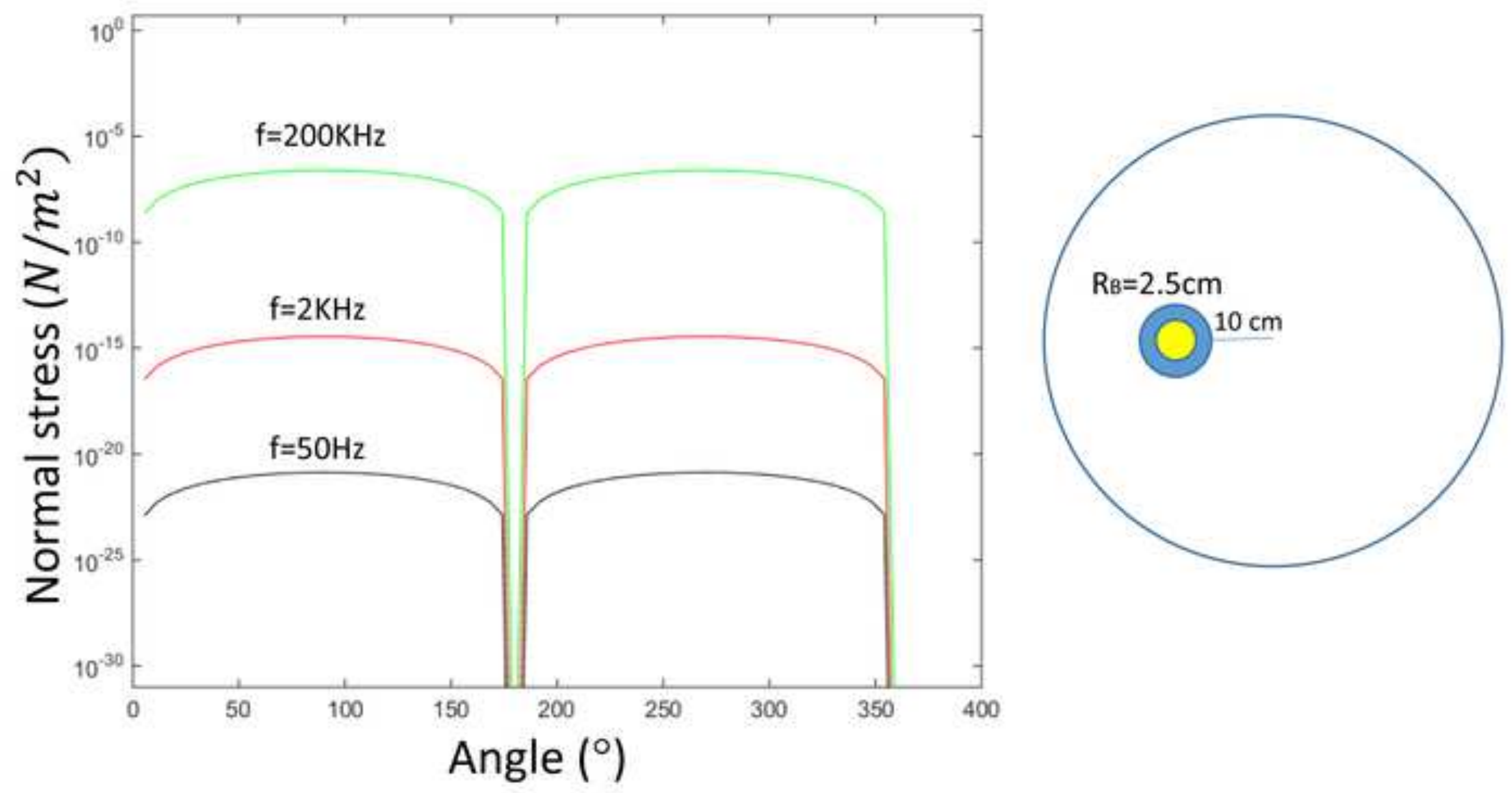

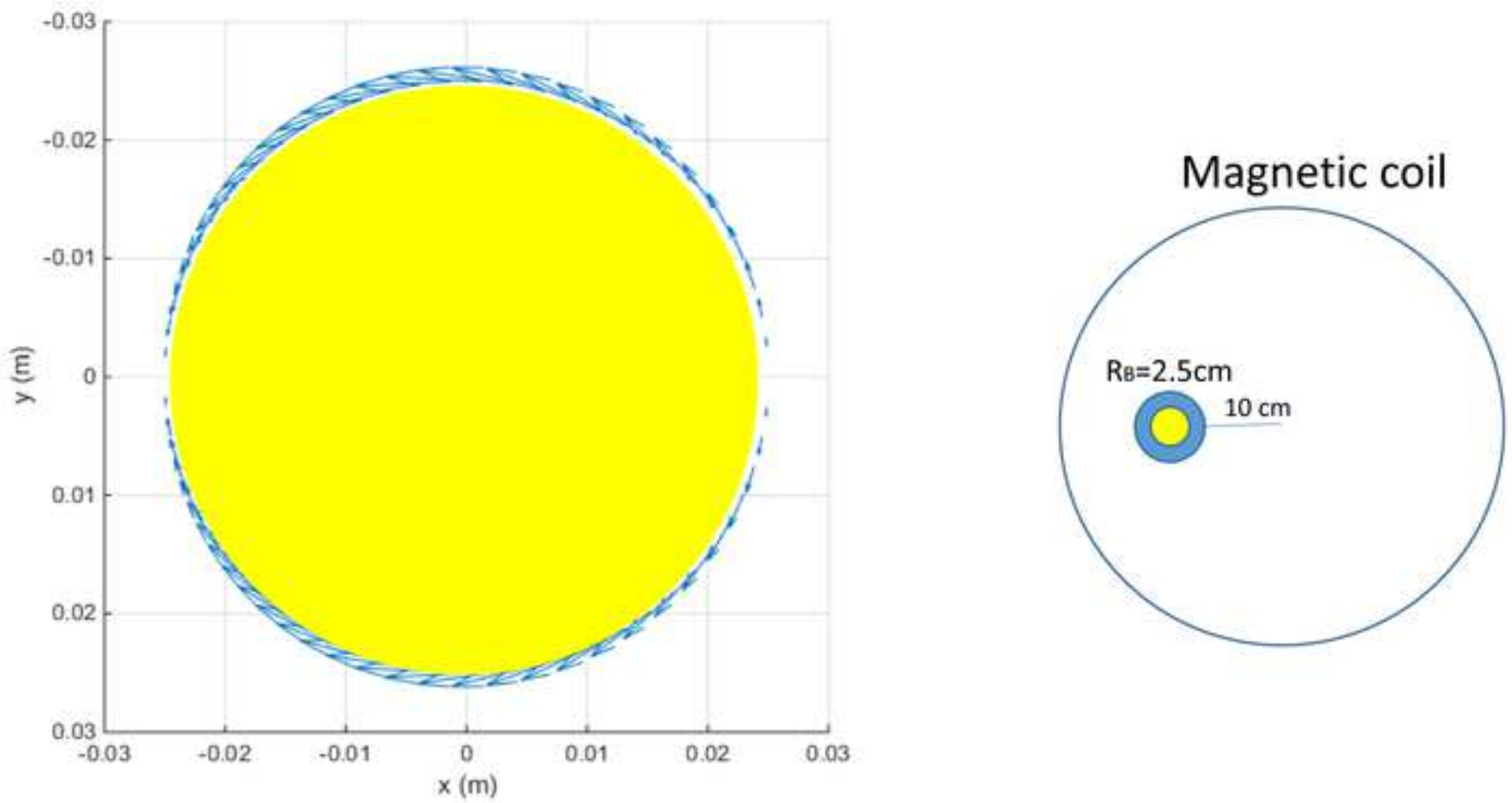


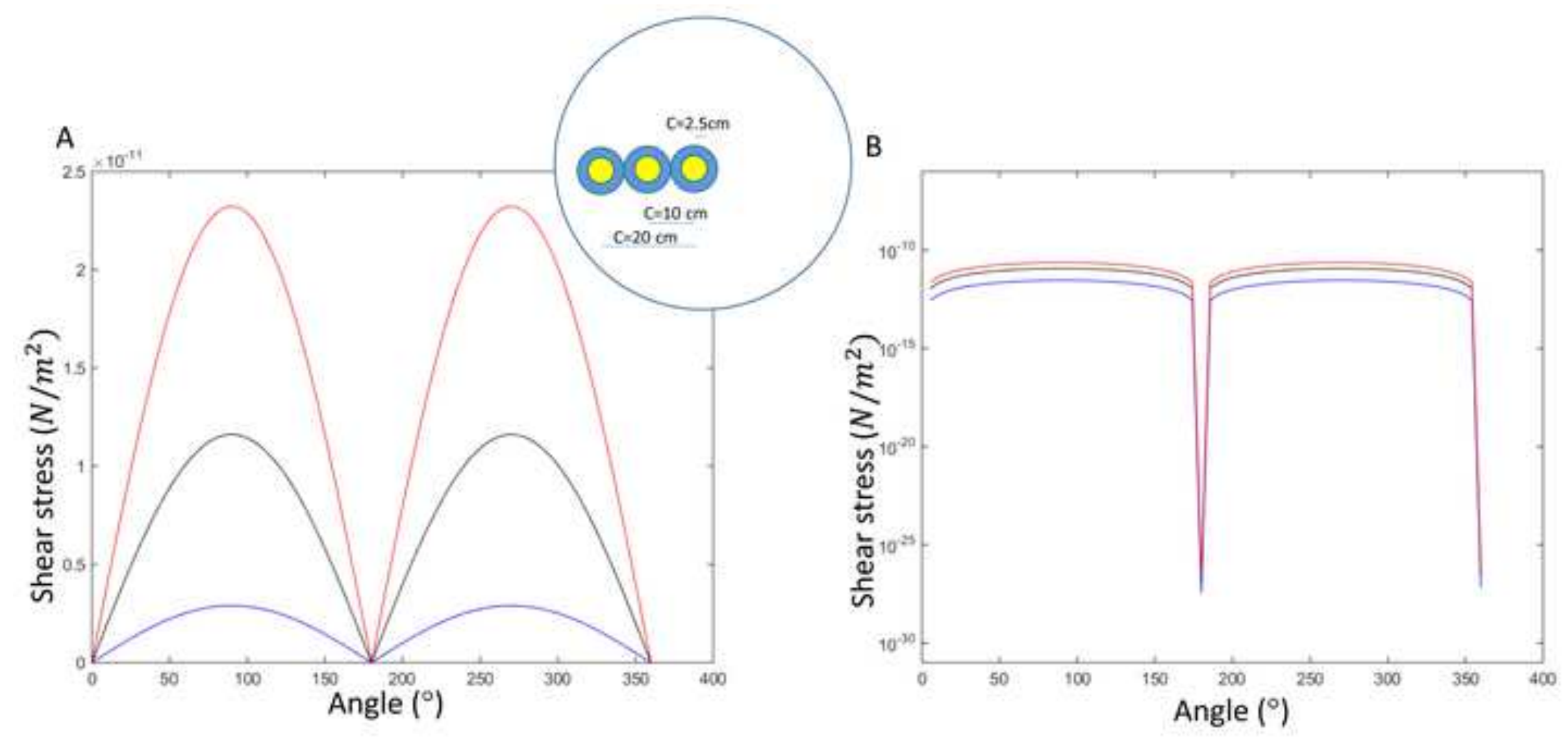



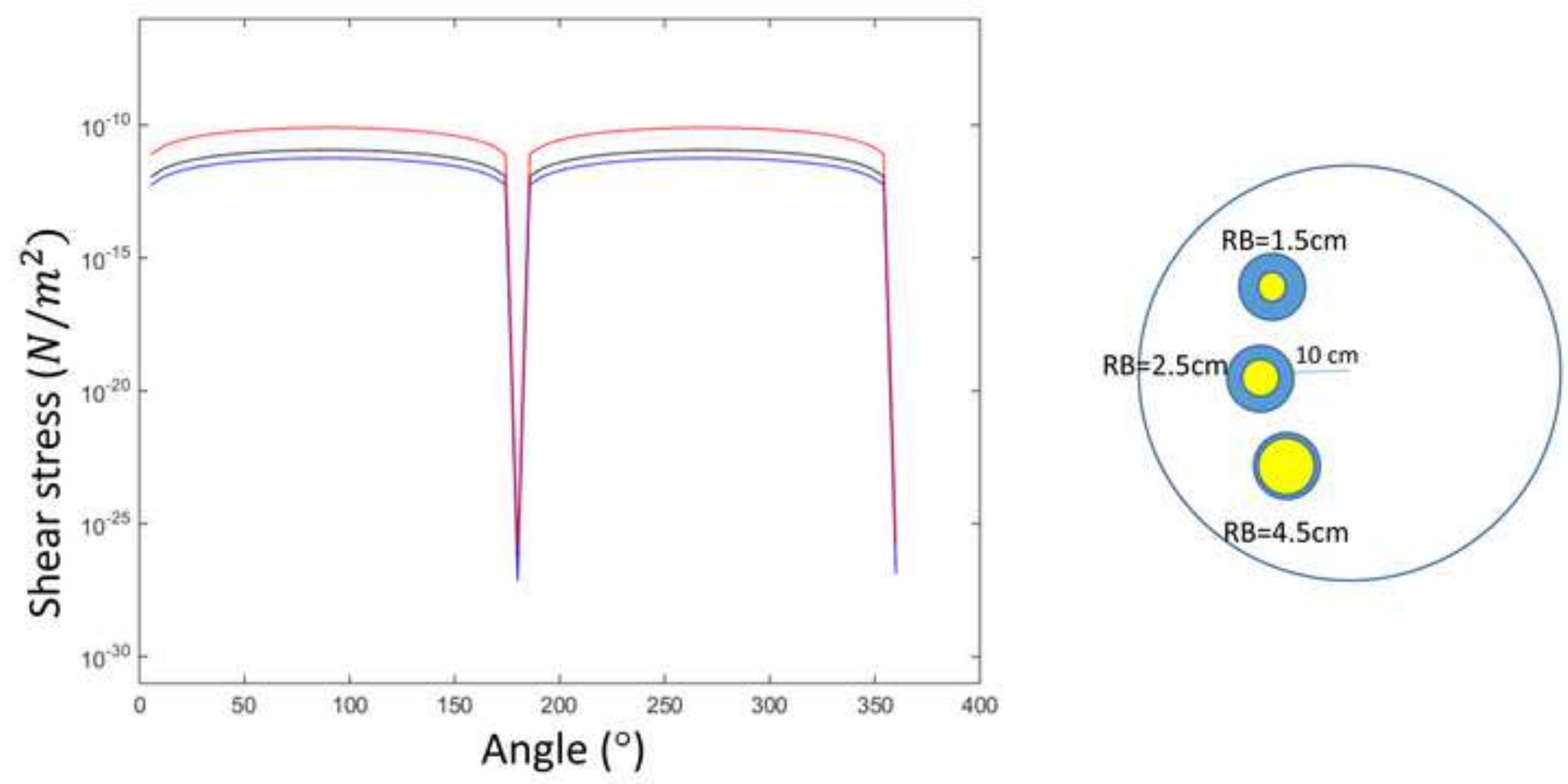

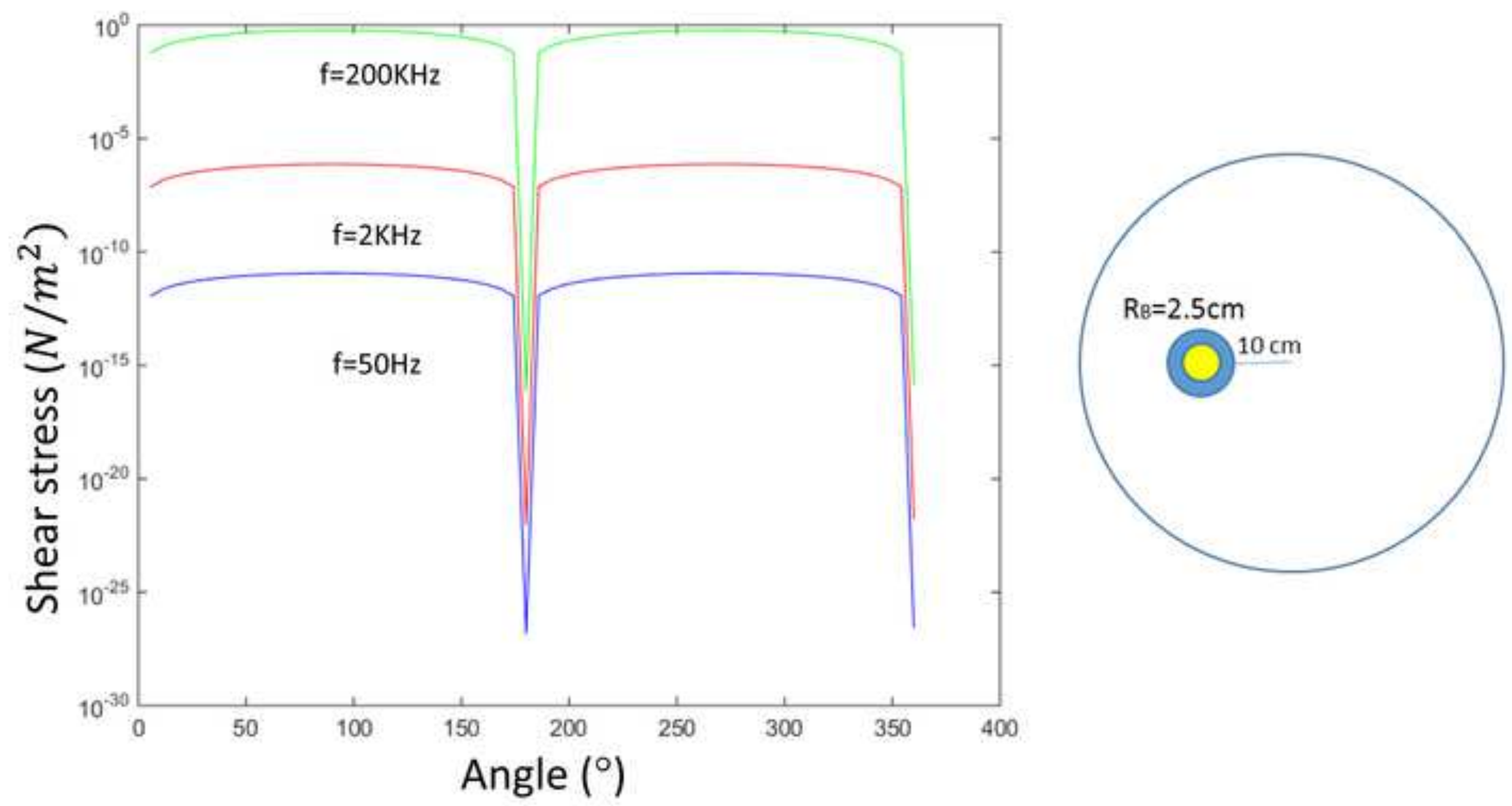

Angle $\left({ }^{\circ}\right)$ 